\title{
6 - COMPOSITION
}

EXERCISE 59: Type a letter to Star Records, 14 Dykelands Road, Barrow-on-Humber, South Humberside, pointing out that you have not received the records you ordered two months ago. Give details of records involved.

Mention that you quoted your Barclaycard number when you ordered the records and have since received a statement from Barclaycard so there is no doubt that Star Records did, in fact, receive your order.

EXERCISE 60: Write a letter to Warren and Graham, Travel Agents, Vicarage Crescent, London SW11 $3 L T$, returning your wife's air ticket. Point out that in one place she is referred to as Master, in another as $\mathrm{M}$ (for male) and in a third place as a child. Ask them to have the ticket replaced with one correctly made out as you do not wish to be put in the position of having to explain away these mistakes to an airport official at 5.20 a.m. which is the time you leave for home after your continental holiday.

EXERCISE 61: Type a letter to Mr. B. J. Johnson of 14 Sandy Street, Warrington, WA1 1SR, thanking him for his letter of yesterday. He asked about three-bedroom houses available at the moment. Give him details of all three-bedroom houses mentioned in Exercise 93.

EXERCISE 62: Type a letter to Kenforest Ltd., Chadwick Street, Bolton, Lancs. BL2 1JW, about a food mixer you bought two weeks ago. Although you followed the instructions carefully when using the glass bowl, it developed a large crack after you had used it only twice. Point out that you fully appreciate that their guarantee does not cover glass but suggest, tactfully, that the bowl is now useless after being used only twice and this does not, in your opinion, represent fair wear and tear. Invite their comments.

EXERCISE 63: Your employer has to go to Leicester on business and has asked you to book a room with bath for himself and his wife at the Royal Hotel, Scraptoft, Leicester, LE7 9SU, for the nights of September 10th, 11 th and 12th. He expects to have lunch and dinner out on 11 th and 12th so wants to book for bed and breakfast only but would like an evening meal on the 10th when he and his wife expect to arrive about 8 p.m.

Write a suitable letter to the hotel.

EXERCISE 64: Type a memo to your employer confirming the accommodation and meal arrangements in connection with Exercise 63.

EXERCISE 65: Type a memo from the Exhibition Secretary to Mr. L. Williams telling him of the changed dates mentioned in Exercise 84, and asking him what he considers will be the best way of informing competitors.

EXERCISE 66: Type a letter from Mr. Williams in answer to the memo mentioned in Exercise 65. Mr. Williams lives at 13 Rosethorn Avenue, St. Albans. Herts. AL1 2DY, and the Exhibition Secretary is Mr. G. F. Rose, of 13 Laburnum Grove, St. Albans, AL3 2PJ.

EXERCISE 67: Type a letter to three local painters (use your local directory to supply names and addresses) asking for a quotation for the painting of the outside of your house . including detached garage and garden shed - and ask when they could start work if you accept their quotation.

EXERCISE 68: Type a letter to Pricedown Discount Co. of 19 Park Road, Leeds, LS3 1AA (see Exercise 87 ), ordering a record cabinet, a telephone seat and an oval coffee table. Say you enclose cheque and quote the amount.

EXERCISE 69: Staff in your firm are allowed to use the office duplicator to run off private stencils in connection with the clubs and organisations to which they belong.

In order to help those who are not very sure how to use the duplicator type out a set of clear, numbered instructions about:

(a) using the duplicator to the best advantage,

(b) storing stencils.

Exercises $59-69$ 